\title{
Crescimento Inicial da SoJa sob EFeito de Resíduos de SoRgo ${ }^{1}$
}

\author{
Early Growth of Soybean as Affected by Sorghum Crop Residues
}

\author{
OLIBONE, D. ${ }^{2}$, CALONEGO, J.C. ${ }^{2}$, PAVINATO, P.S. ${ }^{2}$ e ROSOLEM, C.A. ${ }^{3}$
}

\begin{abstract}
RESUMO - O presente trabalho foi desenvolvido em casa de vegetação na Faculdade de Ciências Agronômicas - UNESP, com o objetivo de determinar o efeito no crescimento inicial da soja e na formação do sistema radicular ao longo do tempo da presença de resíduos de sorgo-deguiné e forrageiro. As unidades experimentais constituíram-se de tubos de PVC (rhizotron) com volume de terra de $16 \mathrm{dm}^{-3}$. O delineamento experimental utilizado foi inteiramente casualizado num fatorial $2 \times 3$, sendo duas variedades de sorgo e três manejos dos resíduos de sorgo, com quatro repetições. A palha de sorgo-de-guiné na superfície do solo levou à diminuição na saturação do solo por bases. As palhas de sorgo de ambas as variedades, na superfície do solo, prejudicaram o crescimento da soja, o que também foi observado no caso das raízes do sorgo forrageiro. Resíduos culturais do sorgo-de-guiné, principalmente a palha, são os responsáveis por menores crescimentos das partes aérea e radicular da soja e, conseqüentemente, pelo menor acúmulo de nutrientes.
\end{abstract}

Palavras-chave: alelopatia, crescimento radicular, rotação de culturas.

\begin{abstract}
This experiment was carried out in a greenhouse at Faculdade de Ciências Agronômicas - UNESP, Botucatu, São Paulo, to evaluate early growth and root system formation of soybean in the presence of Guinea and forage sorghum crop residues. The experimental units consisted of PVC tubes (rhizotron) with the capacity of $16 \mathrm{dm}^{3}$ of soil. The experimental design was a $2 \times 3$ factorial in complete randomized blocks, with four replicates. Guinea sorghum straw left on the soil surface reduced soil base saturation. Residues of both sorghum varieties left on the soil surface reduced soybean growth. This was also observed in the presence of forage sorghum root system, alone. Guinea sorghum residues, mainly the straw left on the soil surface, decreased soybean nutrient accumulation as well as root and shoot growth.
\end{abstract}

Keywords: allelopathy, root growth, crop rotation.

\section{INTRODUÇÃO}

O sorgo se destaca como alternativa na rotação de culturas no período de outono/ inverno, por tolerar condições desfavoráveis de umidade e produzir boa quantidade de matéria seca com relação $\mathrm{C} / \mathrm{N}$ relativamente alta. Assim, constitui-se em cobertura apropriada para o estabelecimento e/ou a manutenção do sistema de semeadura direta (Correia et al., 2005). Além disso, tem sistema radicular abundante e agressivo, com boa capacidade de penetração em camadas de solo compactadas (Rosolem et al., 2002), o que também é desejável (Magalhães et al., 2000).

Entretanto, os resíduos de muitas espécies interferem no desenvolvimento de outras, como é o caso de observações realizadas em lavouras de soja cultivadas após o sorgo, as quais mostram efeito negativo no estabelecimento do estande de plantas e no desenvolvimento inicial. Há indícios de que o estabelecimento e o desenvolvimento inicial da soja vêm sendo

Recebido para publicação em 16.9.2005 e na forma revisada em 5.5.2006.

2 Pós-graduando em Agricultura pela Faculdade de Ciências Agronômicas, Universidade Estadual Paulista - UNESP, Rua José Barbosa de Barros, 1780, Caixa Postal 237, 18610-307 Botucatu-SP. ${ }^{3}$ Prof. Titular do Departamento de Agricultura, Faculdade de Ciências Agronômicas - UNESP, Botucatu-SP. 
prejudicados pelos compostos alelopáticos liberados pela decomposição da palha do sorgo, como tanino, alguns ácidos orgânicos e graxos, entre outros.

A alelopatia é definida como qualquer efeito direto ou indireto, benéfico ou prejudicial, de uma planta ou de microrganismos sobre outra planta, mediante produção de compostos químicos que são liberados no ambiente (Rice, 1984). O sorgo possui a capacidade de exsudar alguns compostos químicos alelopáticos por meio dos pêlos radiculares e da parte aérea (Peixoto \& Souza, 2002).

Segundo Almeida (1991), diversos ácidos aromáticos, aldeídos e fenóis, como derivados do ácido cinânico e benzóico, são conhecidos pelas suas propriedades alelopáticas e têm sido isolados com freqüência em diversas espécies vegetais, nos seus resíduos e no solo circunvizinho às raízes. No caso do sorgo, a degradação de glucosídeos cianogênicos forma aldeídos aromáticos fitotóxicos.

Os sintomas dos efeitos alelopáticos provocados pelas coberturas mortas nas culturas mais citados na literatura são: redução de germinação, falta de vigor vegetativo ou morte das plântulas, amarelecimento ou clorose das folhas, redução do perfilhamento e atrofiamento ou deformação das raízes (Almeida, 1991).

As substâncias químicas liberadas pelos resíduos vegetais deixados sobre a superfície do solo, como o que ocorre no sistema de semeadura direta, têm comportamento diferenciado do que ocorre na incorporação. $\mathrm{Na}$ incorporação, essas substâncias ficam diluídas no volume de solo correspondente à profundidade em que foram enterradas; já na semeadura direta elas se concentram na camada superficial. Dessa forma, como a intensidade dos efeitos alelopáticos depende da concentração dos aleloquímicos, a sua ação é mais pronunciada. Além disso, a liberação desses produtos da cobertura morta é mais lenta, fazendo com que os efeitos perdurem por mais tempo (Almeida, 1991).

O presente trabalho teve como objetivo determinar o efeito da presença de resíduos de sorgo-de-guiné e sorgo forrageiro sobre o crescimento inicial e a formação do sistema radicular da cultura da soja.

\section{MATERIAL E MÉTODOS}

O experimento foi conduzido em casa de vegetação da Faculdade de Ciências Agronômicas - UNESP, em Botucatu - SP. O solo, classificado como Latossolo Vermelho distroférrico (Embrapa, 1999) de textura média (630 $\mathrm{g} \mathrm{kg}^{-1}$ de areia, $40 \mathrm{~g} \mathrm{~kg}^{-1}$ de silte e $330 \mathrm{~g} \mathrm{~kg}^{-1}$ de argila), foi seco ao ar e peneirado em malha de $2 \mathrm{~mm}$. A análise química anterior (Raij et al., 2001) revelou os seguintes valores: $\mathrm{pH}\left(\mathrm{CaCl}_{2}\right) 4,1 ; 1,0 \mathrm{mg} \mathrm{dm}^{-3}$ de $\mathrm{P}_{\text {resina }} ; 18,0 \mathrm{~g} \mathrm{dm}^{-3}$ de matéria orgânica; 75,0 $\mathrm{mmol}_{\mathrm{c}} \mathrm{dm}^{-3} \mathrm{de} \mathrm{H}+\mathrm{Al} ; 0,1 \mathrm{mmol}_{\mathrm{c}} \mathrm{dm}^{-3} \mathrm{de}$ $\mathrm{K} ; 4,0 \mathrm{mmol}_{\mathrm{c}} \mathrm{dm}^{-3} \mathrm{de} \mathrm{Ca} ; 1,0 \mathrm{mmol}_{\mathrm{c}} \mathrm{dm}^{-3} \mathrm{de}$ Mg; 5, $1 \mathrm{mmol}_{\mathrm{c}} \mathrm{dm}^{-3} \mathrm{de} \mathrm{SB} ; 81,1 \mathrm{mmol}_{\mathrm{c}} \mathrm{dm}^{-3} \mathrm{de}$ CTC; e 6,3\% de saturação por bases (V). Foi aplicado calcário dolomítico (CaO: 28\%, MgO: 20\% e PRNT: 95\%) para elevar a saturação por bases a 70\% (Raij et al., 1996). O solo foi umedecido à capacidade de campo e acondicionado sob lona plástica por 20 dias. Em seguida, foi seco ao ar e adubado com $100 \mathrm{mg} \mathrm{dm}^{-3}$ de N (uréia), $150 \mathrm{mg} \mathrm{dm}^{-3}$ de $\mathrm{P}$ (superfosfato simples) e $150 \mathrm{mg} \mathrm{dm}^{-3}$ de $\mathrm{K}$ (cloreto de potássio).

O delineamento experimental utilizado foi o inteiramente casualizado, com quatro repetições, em um esquema fatorial $(2 \times 3)$, constituído de duas variedades de sorgo (guiné e forrageiro) e três manejos dos resíduos (palha + raiz, palha e raiz).

Foram cultivadas duas variedades de sorgo (Sorghum vulgare): sorgo-de-guiné e sorgo forrageiro (cultivar Nutrimax). As sementes foram pré-germinadas em laboratório, para minimizar as variações de tempo de emergência existente entre as espécies. Foi realizado o transplante de 25 plântulas por vaso, e após cinco dias fez-se o desbaste, deixando 15 plantas. O teor de água foi monitorado diariamente e corrigido sempre que necessário, para que permanecesse próximo à capacidade de campo.

As unidades experimentais constituíramse de tubos de PVC com diâmetro de $0,26 \mathrm{~m}$ e altura de 0,60 m. Os tubos foram cortados ao meio no sentido longitudinal, formando uma face plana, na qual se instalou uma parede de vidro (rhizotron), a qual propiciava o acompanhamento visual do crescimento radicular das culturas. O volume de terra contido em cada unidade experimental foi de $16 \mathrm{dm}^{-3}$. 
No $38^{\circ}$ dia de cultivo, as plantas de sorgo foram submetidas à aplicação foliar de herbicida não-seletivo de ação sistêmica (Glyphosate), na dose de $2,4 \mathrm{~kg} \mathrm{ha}^{-1}$ de ingrediente ativo. Decorridos oito dias da dessecação, os restos vegetais do sorgo foram cortados na altura do colo e picados em fragmentos de aproximadamente 0,05 $\mathrm{m}$ de comprimento, para em seguida serem depositados na superfície do solo dos rhizotrons, de acordo com cada tratamento, na quantidade equivalente a 8,0 toneladas de matéria seca por hectare. A análise química da parte aérea, com a quantidade de nutrientes depositada na superfície, está descrita na Tabela 1.

A soja foi cultivada nos tubos (rhizotrons) sobre os resíduos de duas variedades de sorgo, sob a influência de três manejos desses resíduos, como segue: 1 - palha de sorgo na superfície do solo e sistema radicular de sorgo-deguiné $(\mathrm{P}+\mathrm{R}) ; 2$ - palha de sorgo-de-guiné $(\mathrm{P})$ na superfície do solo; 3 - palha na superfície do solo e sistema radicular de sorgo forrageiro $(\mathrm{P}+\mathrm{R}) ; 4$ - palha de sorgo forrageiro $(\mathrm{P})$ na superfície do solo; 5 - sistema radicular de sorgo-de-guiné (R); e 6 - sistema radicular de sorgo forrageiro (R). Para padronizar as condições de luminosidade, temperatura e umidade do solo, foram depositados fragmentos de esponja inerte na superfície dos vasos não contemplados com a deposição de palha em superfície.

Após o corte e deposição da palha de sorgo na superfície dos vasos, foi realizado transplante de três sementes pré-germinadas de soja (Embrapa 48) por vaso, e, após o estabelecimento destas, foram deixadas duas plântulas por vaso. Nessa ocasião, foi fixado um filme transparente de plástico na parede de vidro dos rhizotrons, os quais foram inclinados a $15^{\circ}$ para possibilitar o crescimento de parte do sistema radicular paralelamente ao vidro. A fim de evitar a incidência de luz no vidro e,

Tabela 1 - Quantidade de nutrientes presente na palha de cada variedade de sorgo, equivalente à aplicação de $8 \mathrm{Mg} \mathrm{ha}^{-1}$

\begin{tabular}{|l|c|c|c|c|c|}
\hline \multirow{2}{*}{ Variedade } & $\mathrm{N}$ & $\mathrm{P}$ & $\mathrm{K}$ & $\mathrm{Ca}$ & $\mathrm{Mg}$ \\
\cline { 2 - 6 } & \multicolumn{5}{|c|}{$\left(\mathrm{kg} \mathrm{ha}^{-1}\right)$} \\
\hline Sorgo Forrageiro & 110,4 & 10,2 & 154,1 & 154,4 & 19,2 \\
Sorgo-de-guiné & 115,2 & 10,5 & 167,5 & 176,8 & 22,1 \\
\hline
\end{tabular}

com isso, a inibição do crescimento radicular, instalou-se uma placa de madeira laminada.

Decorridos três dias do transplante, iniciou-se a avaliação do crescimento do sistema radicular por meio de marcações no filme plástico, com canetas coloridas, das raízes que cresceram paralelamente ao vidro. As avaliações repetiram-se em intervalos de três dias, até o $21^{\circ}$ dia.

Após esse período, as plantas foram cortadas na altura do colo, para determinação da produção de matéria seca da parte aérea e posterior análise química, segundo método relatado por Malavolta et al. (1997). O solo foi retirado dos vasos e homogeneizado para coleta de amostra, a qual foi utilizada para análise química (Raij et al., 2001), e o restante passado em peneiras de malha de 2,0 $\mathrm{mm}$ com auxílio de jatos de água, para separação das raízes de soja. Estas foram armazenadas em solução etílica (30\%) e, posteriormente, analisadas quanto ao comprimento total e diâmetro médio, em scanner e software Winrhizo. As mesmas raízes foram secas em estufa de circulação forçada de ar a $60{ }^{\circ} \mathrm{C}$, para determinação da produção de matéria seca. Os filmes plásticos, com as anotações de crescimento radicular da soja ao longo do tempo, foram avaliados seguindo metodologia proposta por Tennant (1975), considerando-se as diversas datas de amostragem.

Os dados obtidos foram submetidos à análise de variância e as médias comparadas pelo teste $t$ (LSD) a $5 \%$ de probabilidade.

\section{RESULTADOS E DISCUSSÃO}

Algumas características químicas do solo foram afetadas pelos resíduos de sorgo tanto quando este foi cultivado como quando depositada somente a palha sobre o solo, antecedendo a soja. Não houve diferença para $\mathrm{pH}$ do solo entre as variedades de sorgo. Para os manejos, o pH do solo foi menor com a deposição de palhada de sorgo sobre a superfície, sendo esse efeito observado tanto com o sorgo-de-guiné como com o forrageiro; isso refletiu também nos resultados da acidez potencial do solo, mostrando valores superiores de $\mathrm{H}+\mathrm{Al}$ nesses dois tratamentos (Tabela 2). 
Tabela 2 - Características químicas do solo em razão das variedades de sorgo e do manejo realizado ${ }^{\underline{1} /}$

\begin{tabular}{|c|c|c|c|c|c|c|c|}
\hline \multirow{2}{*}{ Tratamento } & $\mathrm{pH}$ & $\mathrm{P}$ resina & $\mathrm{K}$ & $\mathrm{Ca}$ & $\mathrm{Mg}$ & $\mathrm{H}+\mathrm{Al}$ & $\mathrm{V}$ \\
\hline & $\left(\mathrm{CaCl}_{2}\right)$ & $\left(\mathrm{mg} \mathrm{kg}^{-1}\right)$ & \multicolumn{4}{|c|}{$\left(\mathrm{mmol}_{\mathrm{c}} \mathrm{dm}^{-3}\right)$} & $(\%)$ \\
\hline \multicolumn{8}{|c|}{ (Variedade) } \\
\hline Sorgo-de-guiné & $4,9 \mathrm{a}$ & $60,6 \mathrm{a}$ & $2,9 \mathrm{a}$ & $20,5 \mathrm{a}$ & $4,8 \mathrm{a}$ & $26,9 \mathrm{a}$ & $51,5 \mathrm{a}$ \\
\hline Sorgo forrageiro & $5,0 \mathrm{a}$ & $54,8 \mathrm{a}$ & $2,6 \mathrm{a}$ & $20,6 \mathrm{a}$ & $5,7 \mathrm{a}$ & $25,8 \mathrm{a}$ & $52,5 \mathrm{a}$ \\
\hline \multicolumn{8}{|c|}{ (Manejo) } \\
\hline Palha + raízes & $5,0 \mathrm{a}$ & $52,1 \mathrm{a}$ & $2,7 \mathrm{~b}$ & $19,5 \mathrm{a}$ & $5,3 \mathrm{a}$ & $25,5 \mathrm{~b}$ & $51,4 \mathrm{ab}$ \\
\hline Palha & $4,8 \mathrm{~b}$ & $61,7 \mathrm{a}$ & $3,3 \mathrm{a}$ & $19,7 \mathrm{a}$ & $5,4 \mathrm{a}$ & $28,2 \mathrm{a}$ & $50,2 \mathrm{~b}$ \\
\hline Raízes & $5,0 \mathrm{a}$ & $59,3 \mathrm{a}$ & $2,2 \mathrm{~b}$ & $22,4 \mathrm{a}$ & $4,9 \mathrm{a}$ & $25,1 \mathrm{~b}$ & $54,4 \mathrm{a}$ \\
\hline \multicolumn{8}{|c|}{ Fator de variação (Teste F) } \\
\hline Variedade & ns & ns & ns & ns & ns & ns & ns \\
\hline Manejo & $*$ & ns & * & ns & ns & $*$ & ns \\
\hline Variedade $\mathrm{x}$ manejo & ns & ns & ns & ns & ns & ns & $*$ \\
\hline $\mathrm{CV}(\%)$ & 3,15 & 17,35 & 20,81 & 16,31 & 23,81 & 5,90 & 7,32 \\
\hline
\end{tabular}

${ }^{1 /}$ Médias seguidas de letras iguais não diferem entre si pelo teste $\mathrm{t}(\mathrm{LSD})$ a $5 \%$ de probabilidade. ${ }^{\text {ns }}$ Não-significativo. * Significativo a $5 \%$ de probabilidade.

Guando se avaliou o K no solo, observouse maior concentração na presença de palhada na superfície (Tabela 2), principalmente com resíduos de sorgo-de-guiné. Em relação ao sorgo forrageiro, o aumento do $\mathrm{K}$ do solo somente ocorreu onde foi depositada palha na superfície, porém sem a presença de raízes. Quando se comparam as duas variedades de sorgo, observam-se maiores concentrações de $\mathrm{K}$ no solo na presença de resíduos de sorgode-guiné. Isso pode ser devido ao maior acúmulo e à conseqüente liberação de $\mathrm{K}$ do resíduo dessa variedade (Tabela 1). Calonego et al. (2005), trabalhando com milheto, demonstraram que, à medida que a planta dessecada senesce e recebe chuvas, libera potássio, que é retornado ao solo. Por sua vez, Rosolem et al. (2005), também com milheto, demonstraram que, entre a aplicação do dessecante e a morte das plantas dessecadas, há perda de $\mathrm{K}$ do tecido vegetal para o solo.

Com relação aos demais componentes químicos avaliados no solo, como $\mathrm{P}$, Ca e Mg, não houve diferença significativa entre as variedades e os manejos dos resíduos. No entanto, a saturação por bases (V\%) foi diminuída pela palhada de ambas as variedades de sorgo.

A análise de variância não mostrou efeito das variedades de sorgo sobre a matéria seca das partes aérea e radicular, no comprimento e na área das raízes de soja (Tabela 3). Os manejos dos resíduos de sorgo apresentaram efeitos significativos somente sobre o comprimento radicular e a área de raiz. Houve interação significativa entre variedade e manejo para as variáveis de crescimento das partes aérea e radicular avaliadas.

O crescimento das partes aérea e radicular da soja foi favorecido quando esta foi cultivada em sucessão ao sorgo-de-guiné, porém na ausência de palha. Quanto ao sorgo forrageiro, este não interferiu na produção de matéria seca, tanto da parte aérea como da radicular da soja (Tabela 4).

No entanto, o comprimento e a área radicular da soja foram superiores na ausência de palha, para sorgo-de-guiné, mostrando que a

Tabela 3 - Análise de variância dos valores correspondentes aos resultados de crescimento das partes aérea e radicular da soja, após 21 dias de cultivo, em função das variedades de sorgo e do manejo realizado

\begin{tabular}{|l|c|c|c|c|}
\hline \multicolumn{1}{|c|}{$\begin{array}{c}\text { Fator de } \\
\text { variação }\end{array}$} & $\begin{array}{c}\text { Matéria } \\
\text { seca } \\
\text { Parte aérea }\end{array}$ & $\begin{array}{c}\text { Matéria } \\
\text { seca } \\
\text { Raízes }\end{array}$ & $\begin{array}{c}\text { Comprimento } \\
\text { radicular }\end{array}$ & $\begin{array}{c}\text { Área de } \\
\text { raiz }\end{array}$ \\
\hline Variedade (V) & $\mathrm{ns}$ & $\mathrm{ns}$ & $\mathrm{ns}$ & $\mathrm{ns}$ \\
\hline Manejo (M) & $\mathrm{ns}$ & $\mathrm{ns}$ & $*$ & $*$ \\
\hline $\mathrm{V} \times \mathrm{M}$ & $*$ & $*$ & $*$ & $*$ \\
\hline $\mathrm{CV}(\%)$ & 19,39 & 27,67 & 25,24 & 23,75 \\
\hline
\end{tabular}

(ns Não-significativo. * Significativo a $5 \%$ de probabilidade pelo teste $\mathrm{t}$ (LSD). 
Tabela 4 - Desdobramento da interação entre as variedades de sorgo e os manejos dos resíduos no crescimento das partes aérea e radicular da soja, após 21 dias de cultivo ${ }^{\underline{1}}$

\begin{tabular}{|c|c|c|c|}
\hline \multirow{2}{*}{ Variedade } & \multicolumn{3}{|c|}{ Manejo dos resíduos } \\
\hline & Palha + Raiz & Palha & Raiz \\
\hline & \multicolumn{3}{|c|}{ Matéria seca da parte aérea (g por planta) } \\
\hline Sorgo-de-guiné & $0,69 \mathrm{aB}$ & $0,52 \mathrm{aB}$ & $0,93 \mathrm{aA}$ \\
\hline \multirow[t]{2}{*}{ Sorgo forrageiro } & $0,69 \mathrm{aA}$ & $0,69 \mathrm{aA}$ & $0,65 \mathrm{bA}$ \\
\hline & \multicolumn{3}{|c|}{ Matéria seca de raízes (g por planta) } \\
\hline Sorgo-de-guiné & $0,20 \mathrm{aB}$ & $0,12 \mathrm{aB}$ & $0,28 \mathrm{aA}$ \\
\hline \multirow[t]{2}{*}{ Sorgo forrageiro } & $0,19 \mathrm{aA}$ & $0,20 \mathrm{aA}$ & $0,17 \mathrm{bA}$ \\
\hline & \multicolumn{3}{|c|}{ Comprimento radicular ( $\mathrm{cm}$ por planta) } \\
\hline Sorgo-de-guiné & $1.722 \mathrm{aB}$ & $1.095 \mathrm{bB}$ & $2.632 \mathrm{aA}$ \\
\hline \multirow[t]{2}{*}{ Sorgo forrageiro } & $1.600 \mathrm{aA}$ & $1.853 \mathrm{aA}$ & $2.104 \mathrm{aA}$ \\
\hline & \multicolumn{3}{|c|}{ Área de raiz $\left(\mathrm{cm}^{2}\right.$ por planta) } \\
\hline Sorgo-de-guiné & $256 \mathrm{aB}$ & $171 \mathrm{bB}$ & $392 \mathrm{aA}$ \\
\hline \multirow[t]{2}{*}{ Sorgo forrageiro } & $244 \mathrm{aA}$ & $274 \mathrm{aA}$ & $315 \mathrm{aA}$ \\
\hline & \multicolumn{3}{|c|}{ Relação parte aérea/área radicular $\left(\mu \mathrm{g} \mathrm{cm}^{-2}\right)$} \\
\hline Sorgo-de-guiné & 2,69 & 3,05 & 2,37 \\
\hline Sorgo forrageiro & 2,82 & 2,52 & 2,06 \\
\hline
\end{tabular}

1/ Médias seguidas pela mesma letra, minúscula nas colunas e maiúscula nas linhas, não diferem entre si pelo teste t (LSD) a 5\% de probabilidade.

presença de palha desse cultivar proporcionou inibição do crescimento do sistema radicular. Isso, talvez, se deva à liberação de compostos alelopáticos prejudiciais ao crescimento radicular da soja. Esses compostos seriam os responsáveis pelo aumento da acidez do solo, como mostram os dados da Tabela 2.

Correia et al. (2005) comprovaram que extratos foliares de alguns híbridos de sorgo inibem o crescimento da radícula da soja em até 54\%; entretanto, esses efeitos não foram comprovados com extratos de raízes e caule, mostrando que os efeitos alelopáticos são mais expressivos quando na presença de folhas de sorgo - resultados esses semelhantes aos dados deste trabalho. A ação alelopática de resíduos vegetais também foi comprovada por Guenzi et al. (1967), os quais mostram que os extratos aquosos da resteva de trigo, aveia, milho e sorgo contêm substâncias alelopáticas que são tóxicas para as plântulas de trigo, na ordem crescente de fitoxicidade em que foram mencionadas. Quando essas restevas foram deixadas em decomposição sobre o solo, a do trigo e a da aveia perderam a ação alelopática em oito semanas, enquanto a do milho e a do sorgo a mantiveram por 22 a 28 semanas.
Putnam \& Frank (1979), ao depositarem sobre o solo $4.450 \mathrm{~kg}$ de palha de diversas espécies, verificaram que a de sorgo foi a mais eficiente em reduzir a densidade de plantas daninhas em pomares de cerejeira e macieira.

A relação matéria seca de parte aérea por área de raiz da soja foi menor quando a planta foi cultivada na presença somente de raízes, sem palha na superfície, tanto de sorgo-de-guiné como de forrageiro (Tabela 4). Isso mostra que houve incremento na área radicular sem que houvesse aumento proporcional no crescimento da parte aérea. Nessa situação, a cultura subseqüente - no caso, a soja - poderia ser beneficiada em condições de estresse hídrico, apresentando maior área de exploração radicular.

A análise de variância não mostrou efeito significativo das variedades de sorgo sobre os nutrientes acumulados pela soja (Tabela 5). No entanto, evidenciou efeito significativo do manejo dos resíduos sobre os nutrientes acumulados e interação entre variedade e manejo de resíduos de sorgo.

Na tabela de desdobramento da interação, é possivel observar que a palhada de sorgode-guiné foi responsável pelo menor acúmulo dos nutrientes $\mathrm{N}$, Ca e $\mathrm{Mg}$ na parte aérea da soja, após 21 dias de cultivo (Tabela 6). Esses resultados estão diretamente relacionados com as menores produções de matéria seca da parte aérea (Tabela 4). Em contrapartida, a presença somente de raízes de sorgo-de-guiné proporcionou maior produção de matéria seca tanto de parte aérea como de raiz, refletindo no maior acúmulo de nutrientes na parte aérea da soja.

Tabela 5 - Análise de variância dos valores correspondentes ao acúmulo de nutrientes na parte aérea da soja, após 21 dias de cultivo, em função das variedades de sorgo e do manejo realizado

\begin{tabular}{|l|c|c|c|c|c|}
\hline Fator de variação & $\mathrm{N}$ & $\mathrm{P}$ & $\mathrm{K}$ & $\mathrm{Ca}$ & $\mathrm{Mg}$ \\
\hline Variedade (V) & $\mathrm{ns}$ & $\mathrm{ns}$ & $\mathrm{ns}$ & $\mathrm{ns}$ & $\mathrm{ns}$ \\
\hline Manejo (M) & $*$ & $*$ & $*$ & $*$ & $*$ \\
\hline V x M & $*$ & $*$ & $*$ & $*$ & $*$ \\
\hline CV\% & 21,99 & 26,15 & 22,17 & 21,45 & 22,00 \\
\hline
\end{tabular}

${ }^{\text {ns }}$ Não-significativo. * Significativo a $5 \%$ de probabilidade pelo teste $\mathrm{t}$ (LSD). 
Tabela 6 - Desdobramento da interação entre cultivares de sorgo e manejos no acúmulo de nutrientes na parte aérea da soja, após 21 dias de cultivo ${ }^{1 /}$

\begin{tabular}{|c|c|c|c|}
\hline \multirow{2}{*}{ Variedade } & \multicolumn{3}{|c|}{ Manejo dos resíduos } \\
\hline & Palha + Raiz & Palha & Raiz \\
\hline & \multicolumn{3}{|c|}{ Nitrogênio ( $\mu$ g por planta) } \\
\hline Sorgo-de-guiné & $18,6 \mathrm{aB}$ & $15,6 \mathrm{bB}$ & $32,3 \mathrm{aA}$ \\
\hline \multirow[t]{2}{*}{ Sorgo forrageiro } & $22,2 \mathrm{aA}$ & $25,6 \mathrm{aA}$ & $22,8 \mathrm{bA}$ \\
\hline & \multicolumn{3}{|c|}{ Fósforo ( $\mu \mathrm{g}$ por planta) } \\
\hline Sorgo-de-guiné & $0,66 \mathrm{aB}$ & $0,35 \mathrm{aC}$ & $1,10 \mathrm{aA}$ \\
\hline \multirow[t]{2}{*}{ Sorgo forrageiro } & $0,74 \mathrm{aA}$ & $0,49 \mathrm{aA}$ & $0,68 \mathrm{bA}$ \\
\hline & \multicolumn{3}{|c|}{ Potássio ( $\mu$ g por planta) } \\
\hline Sorgo-de-guiné & $16,5 \mathrm{aB}$ & $11,1 \mathrm{aC}$ & $22,2 \mathrm{aA}$ \\
\hline \multirow[t]{2}{*}{ Sorgo forrageiro } & $17,0 \mathrm{aA}$ & $13,3 \mathrm{aA}$ & $13,6 \mathrm{bA}$ \\
\hline & \multicolumn{3}{|c|}{ Cálcio ( $\mu \mathrm{g}$ por planta) } \\
\hline Sorgo-de-guiné & $12,9 \mathrm{aB}$ & $9,5 \mathrm{bB}$ & $24,4 \mathrm{aA}$ \\
\hline \multirow[t]{2}{*}{ Sorgo forrageiro } & $13,9 \mathrm{aA}$ & $15,8 \mathrm{aA}$ & $16,0 \mathrm{bA}$ \\
\hline & \multicolumn{3}{|c|}{ Magnésio ( $\mu \mathrm{g}$ por planta) } \\
\hline Sorgo-de-guiné & $2,5 \mathrm{aB}$ & $1,9 \mathrm{bB}$ & $5,0 \mathrm{aA}$ \\
\hline Sorgo forrageiro & $2,7 \mathrm{aA}$ & $3,2 \mathrm{aA}$ & $3,3 \mathrm{bA}$ \\
\hline
\end{tabular}

1/ Médias seguidas pela mesma letra, minúscula nas colunas e maiúscula na linhas, não diferem entre si pelo teste t(LSD) a 5\% de probabilidade.
O comprimento radicular acumulado no período de avaliação também revela o efeito depressivo da palha do sorgo-de-guiné (Figura 1), chegando a reduzir em até $61,6 \%$ o comprimento de raízes da soja. Quanto ao sorgo forrageiro, essa redução foi menos expressiva, atingindo 40,1\%, não refletindo no crescimento da parte aérea da soja. Esses resultados mostram que a palha de sorgo-deguiné exerce maior influência no crescimento radicular, refletindo em menor produção de matéria seca de parte aérea da soja, quando comparado com sorgo forrageiro. De acordo com Peixoto \& Souza (2002), as plantas de sorgo possuem a capacidade de exsudar aleloquímicos através dos pêlos radiculares, compostos estes que também são encontrados em sementes, raízes, colmos e folhas em quantidades variáveis, interferindo no manejo das plantas cultivadas - fato este também comprovado por outros autores (Cheema \& Khaliq, 2000; Roth et al., 2000; Correia et al., 2005).

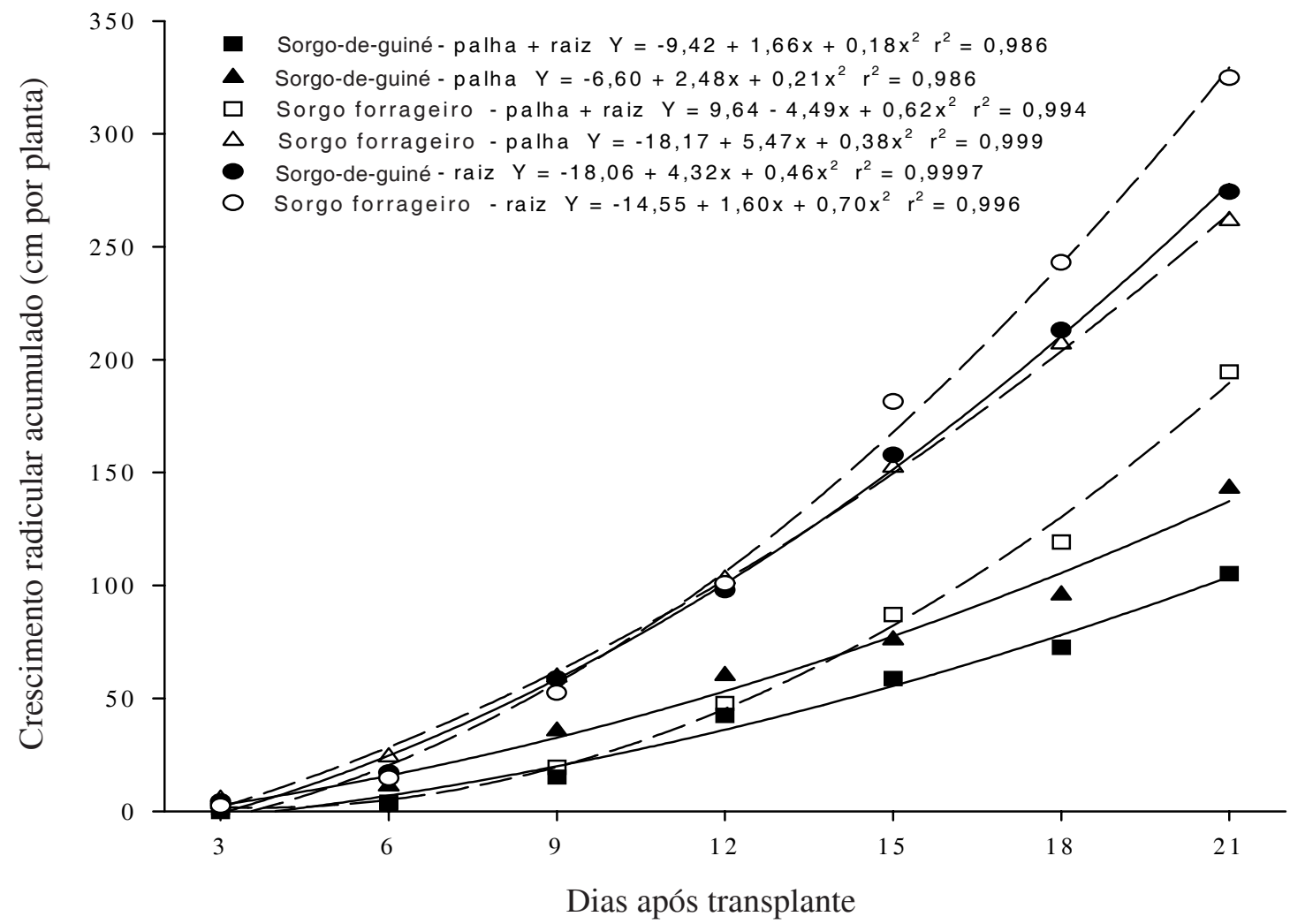

Figura 1 - Curva de ajuste do crescimento radicular acumulado no período inicial da soja, na presença de raiz e/ou palha de sorgo-de-guiné ou forrageiro. 
Outro fator que pode ter influenciado o crescimento inicial da soja em sucessão ao sorgo forrageiro é a redução do $\mathrm{pH}$ e a diminuição na saturação de bases no solo quando a palha dessa variedade permaneceu na superfície do solo. Em ambas as palhas de sorgo na superfície do solo, houve prejuízo no crescimento da soja, o que também foi observado, no caso das raízes, para o sorgo forrageiro.

\section{LITERATURA CITADA}

ALMEIDA, F. S. Efeitos alelopáticos de resíduos vegetais. Pesq. Agropec. Bras., v. 26, n. 2, p. 221-236, 1991.

CALONEGO, J. C.; FOLONI, J. S. S.; ROSOLEM, C. A. Lixiviação de potássio da palha de plantas de cobertura em diferentes estádios de senescência após a dessecação química. R. Bras. Ci. Solo, v. 29, n. 1, p. 99-108, 2005.

CHEEMA, Z. A.; KHALIQ, A. Use of sorghum allelopathic properties to control weeds in irrigated wheat in a semi arid region of Punjab. Agric. Ecosys. Environ., v. 79, p. 105-112, 2000 .

CORREIA, N. M.; CENTURION, M. A. P. C.; ALVES, P. L. C. A. Influência de extratos aquosos de sorgo sobre a germinação e desenvolvimento de plântulas de soja. Ci. Rural, v. 35, n. 3, p. 498-503, 2005.

EMPRESA BRASILEIRA DE PESQUISA AGROPECUÁRIA - EMBRAPA. Sistema brasileiro de classificação de solos. Brasília: CNPS, 1999. 412 p.

GUENZI, W. D.; McCALLA, C.; NORSTADT, F. A. Presence and persistence of phytotoxic substances in wheat, oat, corn and sorghum residues. Agron. J., v. 59, p. 163-165, 1967.
MAGALHÃES, P. C; DURÃES, F. O. M; SCHAFFERT, R. E. Fisiologia da planta de sorgo. Sete Lagoas: Embrapa Milho e Sorgo, 2000. 46 p. (Embrapa Milho e Sorgo Circular Técnica, 3)

MALAVOLTA, E.; VITTI, G. C.; OLIVEIRA, S. A. Avaliação do estado nutricional das plantas: princípios e aplicações. 2.ed. Piracicaba: Potafos, 1997. 319 p.

PEIXOTO, M. F.; SOUZA, I. F. Efeitos de doses de imazomox e densidades de sorgo (Sorghum bicolor (L.) Moench) em soja (Glycine max (L.) Merril) sob plantio direto. Ci. Agrotecnol., v. 26, n. 2, p. 252-258, 2002.

PUTNAM, A. R.; FRANK, J. Use of allelopathic cover crops to inhibit weeds. In: SYMPOSIUM INTERNATIONAL CONGRESS OF PLANT PROTECTION, 9., 1979, Washington. Proceedings... Washington: 1979. p.580-582.

RAIJ, B. van. et al. (Eds.). Recomendações de adubação e calagem para o estado de São Paulo. 2.ed. Campinas: Instituto Agronômico \& Fundação IAC, 1996. 285 p.

RAIJ, B. van. et al. Análise química para avaliação da fertilidade de solos tropicais. Campinas: Instituto Agronômico, 2001. 285 p.

ROSOLEM, C. A.; CALONEGO, J. C.; FOLONI, J. S. S. Potassium leaching from millet straw as affected by rainfall and potassium rates. Comm. Soil Sci. Plant Anal., v. 36, n. 7-8, p. 1063-1074, 2005.

ROSOLEM, C. A.; FOLONI, J. S. S.; TIRITAN, C. S. Root growth and nutrient accumulation in cover crops as affected by soil compaction. Soil Till. Res., v. 65, p. 109-115, 2002.

RICE, E. L. Allelopathy. 2.ed. New York: Academic Press, 1984. $422 \mathrm{p}$.

ROTH, C. M.; SHROYER, J. P.; PAULSEN, G. M. Allelopathy of sorghum on wheat under several tillage systems. Agron. J., v. 92, n. 5, p. 855-860, 2000.

TENNANT, D. A. A test of a modified line intersect method of estimating root length. J. Ecol. v. 63, p. 995-1.001, 1975. 